\title{
Penetrating Open Globe Injury
}

National Cancer Institute

\section{Source}

National Cancer Institute. Penetrating Open Globe Injury. NCI Thesaurus. Code C118869.

Full thickness wound of the eyewall (cornea and/or sclera) caused by the entry of a sharp object into the eye. (adapted from the Birmingham Eye Trauma Terminology System (BETTS)) 